\title{
Is Good News No News?
}

\author{
by Judith Lichtenberg and Douglas MacLean*
}

\section{Introduction}

No news is good news, the saying goes, carrying with it the suggestion that most news, at least as it is reported in the news media, is bad news. The charge is commonly leveled that the media place an undue emphasis on the negative, hawking papers with screaming headlines of gloom and doom, attracting television viewers with color footage of guts and gore. In recent years, in particular, critics have complained that media coverage of technological and other health risks is overly pessimistic, savoring of sensationalism.

By far the most ambitious and provocative research documenting this view is the twenty-five-year study by German sociologists Hans Mathias Kepplinger and Rainer Mathes of coverage of technology in the German print media. Kepplinger and Mathes's claim, for which they have amassed a great deal of evidence, is that media coverage of a variety of technological issues - in particular air, water, and forest pollution, radioactive fallout, and fatal traffic accidents - has become increasingly negative over the last twenty years, while the objective indicators for those issues have shown improvement or at least have not declined. For example: "The press hardly reported water pollution at all during the period of the greatest pollution of the Rhine in the late 1960s and early $1970 \ldots$ The press only emphasized water pollution when the pollution of the Rhine had receded and the regeneration ability of the river in terms of bio-chemical oxygen requirements had increased considerably. In relation to the Rhine there is a contradictory development between the real pollution and reported pollution." Thus, Kepplinger and Mathes conclude, the media do not convey an accurate picture of reality. And, furthermore, "this new portrayal of reality by the media leads to a fundamental change in the public's views".

This view involves two claims: one about media content (a claim about the content of media reports on technological issues compared to "reality") and one about media effects (a causal claim about the impact of such reporting on beliefs and attitudes). Let us examine each of these, beginning with the second.

* This article was condensed and adapted from "The Role of the Media in Risk Communication", in Roger Kasperson and Pieter Jan Stallen, eds., Communicating Risks to the Public: International Perspectives (Dordrecht: D. Reidel, forthcoming). The sources cited are: Hans Mathias Kepplinger and Rainer Mathes, "Artificial Horizons", (unpublished paper, 1987); Allan Mazur, The Dynamics of Technical Controversy (Washington, D.C.: Communications Press, 1981); Report of the Public's Right to Information Task Force of the President's Commission on the Accident at Three Mile Island (Washington, D.C.: U.S. Government Printing Office, 1979); Amos Tversky and Daniel Kahneman, "Prospect Theory: An Analysis of Decisions Under Risks", Econometrica 47 (1979); Kahneman and Tversky, "The Framing of Decisions and the Psychology of Choice", Science 211 (1981); and Elisabeth Noelle-Neumann and Wolfgang Donsbach, "Selective Exposure to Newspaper Content", presented at the International Communication Association Conference, May 21-25, 1987, Montreal. 


\section{Media effects}

The evidence for the view that the media's (inaccurate) portrayal of reality changes public opinion is unclear. It is never possible to be certain, and rarely possible to be even confident, that an effect was caused by media coverage rather than by something else. Part of Kepplinger and Mathes's evidence for their conclusions seems to be that public opinion lags behind media coverage by about a year; that is, negative coverage of an environmental or technological risk is followed by negative public opinion about it. But this may be a case of post hoc, ergo propter hoc reasoning. Journalists and the public may both be responding to some third factor, with journalists quicker to react to events. In that case journalists would appear to be in the vanguard of opinion change, without actually wielding much influence themselves.

Another possible explanation is that as media coverage of a controversy increases, public opposition to it also increases - irrespective of whether the coverage is predominantly negative or not. Allan Mazur, in The Dynamics of Technical Controversy, surmises that exposure to the disagreements among experts in the press makes a technology seem dangerous; even if pro- and anti-technology sentiments are well balanced, the public is inclined to conclude that it's better to be safe than sorry. If this is so, then it is not the negativity of coverage that contributes to negative public opinion; the mere increase in coverage, whether negative or positive, will bring about this effect.

Mazur's view is supported by the conclusions of the Report of the Public's Right to Information Task Force of the President's Comission on the Accident at Three Mile Island. At least part of the impetus for the task force's content analysis was the belief among many critics that American press coverage of Three Mile Island had been unduly alarmist or sensationalist. The content analysis found that, overall, reassuring statements reported by the press far exceeded alarming ones ( 56 to 39 percent). One way to reconcile the impression of alarmism with this finding is via Mazur's view that the mere increase in press coverage of an event or technology contributes to intensifying the sense of danger, even if coverage is not particularly negative. Perhaps people believe that those who speak on behalf of a technology "protest too much".

The idea that the public tends to react negatively to media coverage of environmental and technological risks even where coverage is not predominantly negative suggests that people process negative and positive messages differently. This suggestion is confirmed by the findings of Amos Tversky and Daniel Kahneman, two psychologists studying risk perception. Their work shows that people adopt a reference point from which outcomes or choices are seen as positive or negative, and they tend to react more strongly to options that are negative relative to their reference point than to options that are positive. We tend to be more eager to avoid losses than to secure comparable gains. Thus, if people see a technology as possibly saving lives but also as risking some loss of life, they will weigh the losses more heavily than the gains in deciding whether to support or oppose the technology.

These findings are reinforced by work done by Elisabeth Noelle-Neumann and Wolfgang Donsbach on what factors influence the selection or retention of information by the newspaper reader. The flood of information grows continually, and the question arises: what filters do we use to let some of this information in and leave some out? NoelleNeumann and Donsbach concluded that people are more receptive to negative information 
in the press than positive. Supporters of a technology, for instance, are more likely to be affected by critical information about it than are critics likely to be affected by positive coverage.

These findings - which come from a variety of social scientists in different fields and research areas - all support the view that people process negative and positive information differently. What follows from this? An important conclusion is that, even where people's views are formed largely on the basis of news coverage, it is a large leap from the claim that people have predominantly negative views about an environmental or technological issue, or are unduly alarmed about a given risk, to the view that the media have covered the issue in a sensational or predominantly negative way. And even where news coverage contains more negative than positive messages, it may be the amount and prominence of the coverage, rather than the slant, that has the greater impact on public opinion.

\section{Media content}

What of the charge that the media do not portray an accurate picture of reality because press coverage is unrealistically negative? This view invites difficult questions about the proper role of the media, for it contains an implicit accusation: it suggests that the media ought to be attempting to reflect reality. But this assumption needs to be examined critically.

Indeed, looking at what the media do in communicating risks reveals a deep tension in our expectations of what the media ought to do. Looked at in one way, the criticism that the media do not accurately reflect reality seems a perfectly legitimate and natural one. Of course the media should reflect reality. What, after all, is the alternative? Bias. Distortion. One side of the story. But the view that the media ought at least to strive to mirror "the way things are" conflicts with much of what we know about how the news media do in fact operate. More important, it neglects how they must necessarily operate.

It would be absurd to expect your daily newspaper to give an accurate picture of "reality" full-stop. There is altogether too much reality: subatomic reality, chemical reality, astronomical reality, psychological reality, political reality, economic reality, and lots of other realities, too. At the very most a newspaper can select from among these - omitting, say, subatomic reality as irrelevant to its readers' concerns and concentrating on political and economic reality. But even this is too vast an area. Journalists must find further ways of lopping off large chunks of reality. We begin to draw close to the standard criteria for what's newsworthy, familiar to students of journalism. What's news is what's new, unusual, interesting, important, dangerous, controversial, a change from the norm.

Seen in this way, news coverage is inherently "unrealistic"; it gives us a "distorted" view of the world; it aims, and should aim, at nothing else. Yet it is difficult to reconcile the necessary selectivity of the news media with our interests in truth and objectivity. How do you select a small sample of things and events and trends in the world from the teeming multiplicity without distorting their significance?

Often you don't. Journalists can always be criticized for the criteria they employ in choosing news stories. We may well object to the prevailing practice summarized by a memo that is said to have hung in the newsroom of a British daily: "One Englishman is a story. Ten Frenchmen is a story. One hundred Germans is a story. And nothing ever happens in Chile". But an objection to the particular principles implicit in a given case leaves untouched the wider principle that some criteria must be employed to select from 
the mass of possible news stories. So we can ask: is the media's presumed emphasis on negative aspects of risk issues justified?

To take Kepplinger and Mathes's example, let us assume that water pollution in the Rhine has declined over the last fifteen years, while media coverage of the pollution has increased. Does this indicate a defect in press coverage that ought to be remedied? Not necessarily. First of all, people (journalists or the general public or both) may not have been aware of the Rhine pollution at its peak. What you don't know can hurt you, but it can't scare you. Since the environmental movement only began to gather momentum in the late sixties, it is perfectly plausible that water pollution was greater before people were disturbed by it.

Even if people were aware of the pollution before extensive media coverage (surely they saw it an smelled it), they may not have viewed it as an alterable part of the environment. It is a commonplace that people rebel against their circumstances when they begin to see the possibility of something better, and that this happens not when their circumstances are most dire, but when they have begun to improve. So it is very plausible that those who lived near the Rhine in the early sixties saw its filth as one of the unfortunate but inevitable consequences of civilization.

These points may go some way toward explaining and justifying negative media coverage of pollution even in the face of improving conditions. Pollution may still be excessive, even if there is less today than twenty years ago. We may appreciate its risks more now than when they were greater. And we may hold different values because of previous successes in pollution control, which lead us to demand further improvements in the environment. There is nothing obviously irrational about this process. In covering such issues, journalists can be registering dissatisfaction with a state of affairs despite its improvement over some previous state. They may be reflecting social values, engendering them, or both, but this need not indicate a failure to see "reality" as it is. For the reality at issue here includes people's values and expectations.

Of course the question remains: are journalists partly responsible for increased awareness of pollution and changing values among the public, or are they simply responding to popular trends? No doubt more research in this area can shed some light on this question, but like other chicken-and-egg questions it remains largely unanswerable. Common sense suggests that both factors play a part: journalists, as members of the larger society, respond to social trends (although perhaps more quickly than the typical citizen); at the same time they act as catalysts, spending up those trends.

\section{Conclusion}

The mere fact that negative news coverage of an issue increases while the objective indicators of "negativity" (pollution or other damage) remain the same or even improve in itself indicates no defect in the media's treatment. Deciding what is newsworthy and what the "reality" is that news reporting ought to capture is intrinsically difficult and controversial, and reporters must grapple with these questions every day. We can blame reporters and editors if they simply wrap themselves in First Amendment justifications, as though the social consequences of their decisions were of no importance. But as they try to decide the exact scope and limits of "the news that's fit to print", they are entitled to be Cassandras as well as Pollyannas; other charges must be brought against their nattering beyond that of negativism. 